\title{
Quality matters: reviewing the connections between perceived quality and clothing use time
}

\author{
Maarit Aakko and Kirsi Niinimäki \\ School of Arts, Design and Architecture, Aalto University, Espoo, Finland
}

\begin{abstract}
Purpose - Extending the active lifetimes of garments by producing better quality is a widely discussed strategy for reducing environmental impacts of the garment industry. While quality is an important aspect of clothing, the concept of quality is ambiguous, and, moreover, consumers may perceive quality in individual ways. Therefore, it is important to deepen the general understanding regarding the quality of clothing.

Design/methodology/approach - This paper presents an integrated literature review of the recent discussion of perceived quality of clothing and of the links between quality and clothing lifetimes; 47 selected articles and other literature obtained primarily through fashion/clothing/apparel journals were included in this review.

Findings - The main ideas from the articles are thematized into the following sections: the process of assessment, levels involved in assessment, multidimensional cues of assessment, and quality and clothing use times. The paper highlights that perceiving quality is a process guided by both expectations and experience, and assembles the various aspects into a conceptual map that depicts the connections between the conceptual levels involved in assessing quality. It also illustrates connections between quality and clothing use times.

Research limitations/implications - This paper focused on perceived quality on a conceptual level. Further studies could examine and establish deeper links between quality, sustainability and garment lifespans.

Originality/value - The study draws together studies on perceived quality, presenting the foundational literature and key concepts of quality of clothing. It summarizes them in a conceptual map that may help visualize various aspects affecting the assessment of quality and deepen the general understanding of the quality of garments.
\end{abstract}

Keywords Quality, Perceived quality, Clothing, Integrated literature review, Clothing lifetimes,

Conceptual map

Paper type Literature review

\section{Introduction}

Quality is a concept that is embedded in everyday matters, ranging from food and consumer goods to lifestyle and living environments. It often guides our decisions, and yet its definition is ambiguous.

Quality is a particularly multilayered issue in terms of clothing. On an individual level, quality is considered throughout the life cycle of garments - at the time of purchasing clothing, while using and taking care of it and, lastly, when choosing to discard a garment not

(C) Maarit Aakko and Kirsi Niinimäki. Published by Emerald Publishing Limited. This article is published under the Creative Commons Attribution (CC BY 4.0) licence. Anyone may reproduce, distribute, translate and create derivative works of this article (for both commercial and non-commercial purposes), subject to full attribution to the original publication and authors. The full terms of this licence may be seen at http://creativecommons.org/licences/by/4.0/legalcode

This research was supported by the Academy of Finland's Strategic Research Council's Grant no 327299 Sustainable textile systems: Co-creating resource-wise business for Finland in global textile networks/FINIX consortium. The authors thank the members of Fashion/Textile Futures research group at Aalto University for the valuable feedback on the article and their research assistant Riikka Piippo.
Perceived quality and clothing use time

Received 8 July 2020 Revised 18 January 2021 Accepted 26 February 2021 
JFMM

26,1

108

used anymore. Moreover, quality plays a role even after the first ownership, as - quality allowing - it may have multiple further owners or users (e.g. Ellen MacArthur Foundation, 2017; Niinimäki et al., 2020).

The harmful impacts of the fashion and textile industry, for example, pollution and pressure on the environment, have gained a lot of attention. According to the large report by Ellen MacArthur Foundation (2017), one of the root causes of the industry's wasteful nature is the low clothing utilization and low rates of recycling after use. In the last 15 years, clothing production has approximately doubled, while at the same time clothing utilization has decreased by $36 \%$. This means, a growing amount of nonrenewable resources are extracted to produce clothing that is often used for only a short time (Ellen MacArthur Foundation, 2017).

As the negative environmental impacts of fashion industry become widely acknowledged, numerous strategies are being discussed, examined and applied generally under the frameworks of sustainability and circular economy (e.g. Ellen MacArthur Foundation, 2017; Niinimäki et al., 2020). Keeping clothing, fabric and fibers at their highest value as long as possible and increasing their recycling after use is one of the recommended approaches. It is estimated that if the number of times a garment is worn were doubled on average, the GHG emissions would possibly be $44 \%$ lower (Ellen MacArthur Foundation, 2017). One of the promoted strategies to encourage consumers to use clothing longer and to reduce the quantity of clothing consumed is to focus on producing better quality (Connor-Crabb and Rigby, 2019; Cooper et al., 2013; Ellen MacArthur Foundation, 2017; Klepp et al., 2020; Laitala et al., 2015; Niinimäki et al., 2020; Watson et al., 2017).

For decades, quality has been an essential element of competitive strategy of producers and retailers, serving consumers' needs (Steenkamp, 1990). Lately, there have been comments about the fading of garment quality (Cassidy, 2017; Gabrielli et al., 2013; Joy et al., 2012; Laitala et al., 2015; Niinimäki et al., 2020; Watson et al., 2017), which can be seen as a compromise made for the sake of fast production of low-price, quickly changing fashion. Flaws in the technical quality of the garment, such as holes or tears, are one of the significant reasons for disposing clothing (Laitala et al., 2015).

However, there are many more reasons for garment disposal than merely low technical quality or other defects. Some of these reasons are subjective and contextual, such as change in fashion or in personal style, and not affiliated with the condition of the garment (Joy et al., 2012; Laitala et al., 2015; Maldini et al., 2019). Different types of clothing also have different lifetime expectancy depending on their use purpose (Cooper et al., 2014; Laitala and Klepp, 2015). For example, in terms of "fast fashion" items, acceptable quality seems to be enough as long as it allows achieving a desired style for an affordable price (Gabrielli et al., 2013; Joy et al., 2012). In addition, quality is perceived and experienced in subjective ways, which also influences the length of time and the way a garment is used (ConnorCrabb and Rigby, 2019).

There are various conclusions regarding the role of quality related to the lifespan of clothing. For example, quality, together with aesthetics, is often considered highly important when purchasing clothes (Niinimäki, 2010), and perceived value of clothing is relevant in consumers' attempts of extending garment life (McNeill et al., 2020). Quality is also mentioned by sustainable-minded fashion designers as a foundational aspect of garments when considering sustainability (Karell and Niinimäki, 2020). However, clothing consumption does not always follow predictable paths assumed by the existing sustainable fashion strategies, and therefore may not yield straightforwardly to the anticipated positive environmental gains (Maldini et al., 2019; Niinimäki and Hassi, 2011). Purchasing better quality does not necessarily lead to buying less. Moreover, according to the literature review looking at the relationships between fast fashion, quality and longevity, the connection between intrinsic quality and decreased garment lifetimes is "anecdotal" and requires further research. There is 
also no consensus on what designates quality (Day et al., 2015). Technical quality communicates measurable characteristics of a garment, but these physical features can be interpreted in individual ways influenced by many factors, such as perceptions, needs and goals (Steenkamp, 1990).

Therefore, for advancing knowledge of garment lifetime in relation to sustainability strategies, it is critical to understand the notion of quality from the user's perspective (Connor-Crabb and Rigby, 2019). There are several studies that focus on investigating how quality of clothing is perceived on a subjective level, and which elements communicate quality to a consumer. Acknowledging that finding such a consensus is a challenge, this paper discusses different perspectives to quality by reviewing various aspects of quality in the context of clothing; here, the terms "clothing" and "garments" are used interchangeably and refer to everyday wear, such as jeans, t-shirts, dresses, blouses and outerwear. It aims to provide a broad overview that may enable better understanding of the concept of quality and its links to clothing lifespan.

First, the paper introduces some theories and terminology related to the concept of quality in general. Then, applying the methods of integrated literature review and thematic analysis, the paper delves into the significance and meanings of perceived quality in the context of clothing. With an aim to synthesize the chosen literature, this article presents an integrated summary of the current knowledge and concepts of quality in the context of clothing and outlines a conceptual framework that weaves together the core ideas of perceived quality of garments.

\section{Theoretical background: quality as a concept}

In general terms, "quality" is both a philosophical question and an everyday concept, which defines features of products as well as performance of human individuals, organizations and societies. Although quality is an underlying character that belongs to many contexts, its definition is ambiguous (Anttila and Jussila, 2017). A dictionary definition describes quality, for example, as (1) "the standard of something as measured against other things of a similar kind," (2) "the degree of excellence of something" and (3) "a distinctive attribute or characteristic possessed by someone or something" (Lexico, 2020).

The concept of quality is relative and therefore may have different meanings depending on the context and the set criteria that it is compared to (Lillrank, 1998). There are multiple definitions and/or models that aim to capture the complexity the concept of quality. Different definitions of quality are appropriate in different circumstances, and each has its strengths and weaknesses in relation to measurement, usefulness and relevance of the concept. Most likely an all-encompassing definition of quality does not exist (Reeves and Bednar, 1994). One way to analyze the quality of a product (or service) is to recognize its different dimensions such as performance, features, reliability, conformance, durability, serviceability, aesthetics and perceived quality, and rank them individually (Garvin, 1988).

Garvin (1988) points out that quality can be considered and evaluated differently depending on the chosen viewpoint, such as product, manufacturing, user or value. For example, the user-based definition of quality is a subjective view that describes quality as properties that best satisfy consumers' individual preferences. Adding to these perspectives, Lillrank (1998) discusses also a system-based view on quality. This view takes into account both the intentional and unintentional consequences a product might have on the society and the environment; hence, a good-quality product should not have a negative impact on the environment (Lillrank, 1998).

To simplify, quality is often differentiated into objective and perceived quality, noting that these may be different from each other. "Objective quality" generally refers to measurable and verifiable evaluation of certain product attributes by predetermined quality standards.

\author{
Perceived \\ quality and \\ clothing use \\ time
}


JFMM

26,1
"Perceived quality" can be seen as a consumer's subjective judgment about the quality of a product, and it depends on the individual context; this assessment may be similar to an attitude (Zeithaml, 1988).

The individual process of evaluating quality involves quality cues and quality attributes. "Quality cues" refer to the informational stimuli related to the quality of the product, and can be ascertained through senses. They are utilized prior to consumption, and thus serve as a means to achieve certain ends that are valued by the consumer, such as certain quality attributes or benefits (Steenkamp, 1990). Various cues can be categorized as intrinsic and extrinsic cues. "Intrinsic cues" involve product attributes that cannot be changed without altering the physical characteristics of the product itself, such as material features and performance characteristics. "Extrinsic cues" refer to product-related but external aspects, such as brand, price, reputation, country of origin and marketing (Bubonia, 2014; Olson and Jacoby, 1972; Zeithaml, 1988; Niinimäki, 2015).

"Quality attributes" refer to the functional and psychosocial features of the product. Some quality attributes can be viewed as experience attributes referring to the qualities ascertained by the actual experience with the product. Some other attributes are considered as credence attributes since they cannot be noticed immediately through use, but reveal themselves later, or require additional information given by experts; for example, durability and reliability can be regarded as "credence attributes" (Steenkamp, 1990). According to a conceptual model of the quality perception process by Steenkamp (1990), consumers form perceptions about product quality with the help of extrinsic and intrinsic cues, combined with the acquired information about experience and credence attributes. This process is individual and affected by personal and situational factors.

Since objective and perceived quality are both aspects of quality, Golder et al. (2012) suggest a quality framework that aims to integrate these aspects. It is comprised of three processes: quality production, quality experience and quality evaluation. In this framework, "quality production" is related to the design and production of products, with a focus on performance and reliability. "Quality experience" refers to the process in which customers perceive and experience the attributes of products. "Quality evaluation" represents the conversion of perceived quality attributes into the total assessment of quality. This study also highlights that what customers experience and perceive is filtered through their measurement knowledge, motivation, emotions and expectations; customers do not perceive all attributes they experience and might overlook some attributes entirely.

Along the same lines, Stylidis et al. (2020) expand the definition of perceived quality by integrating product attributes with the personal experience of them. They define perceived quality domain as the "place where the product meaning, form, sensorial properties, and their execution intersect with human experience. Such an experience is driven by the interplay between product quality and its context” (p. 40). Thus, they propose a framework for perceived quality that is based on the primary human senses - visual, tactile, auditory, olfactory and gustatory - involved in the evaluation process. Stylidis et al. (2020) stress that in order to benefit from the theoretical understanding of quality, the industry requires a toolbox of assessment methods.

The same terminologies and definitions related to quality in general are also applied in the context of clothing. Material features can be considered as the objective quality of clothing and evaluated with a variety of methods, such as tests for breaking strength, tear strength, abrasion resistance, colorfastness, effects of laundering (e.g. color and dimensional change), seam strength and pilling (Bubonia, 2014; Cooper et al., 2014). Nevertheless, as summarized above, there are many more features related to quality that cannot be objectively measured, and yet they play a significant role in the assessment of quality. Therefore, it is meaningful to take a closer look at how the perceived quality of clothing is being researched, understood and discussed. 


\section{Materials and method}

The current stream of research considers quality as one of the elements related to the questions of sustainability: low quality is associated with the early disposal of clothing, while the producing of better quality is expected to extend the clothing use times (e.g. Ellen MacArthur Foundation, 2017). Against this backdrop, the aim of this paper is to gain more understanding on the concept of quality in the context of clothing that could be further applied, particularly in the work regarding sustainability.

Building on the concept of quality in the context of clothing and its relationship to clothing lifespan, this paper reviews and synthesizes selected literature of quality in an integrative way (Torraco, 2005) with an aim to provide a wide overview of the concept of perceived quality. Since the integrative literature review can be used, for example, to define concepts and review theories, as well as to create new understanding and/or reconceptualize both mature and emerging topics (Torraco, 2005; Whittemore and Knafl, 2005), it seemed suitable for reviewing the various studies of clothing quality and surveying its links to garment use times. Thus, instead of reviewing and summarizing the existing literature related to the quality of clothing comprehensively, the aim of this integrated review is to present a summary of literature representative of and pertinent to the following research questions:

(1) How is the quality of clothing perceived and what aspects does it involve?

(2) What kinds of connections between quality and garment use times exist?

The literature was selected according to the relevance regarding the research interests of this paper and obtained primarily through a survey focusing on fashion/clothing/apparel journals mainly in the context of design, education, marketing and management. There are numerous technically oriented papers in the field of objective quality assessment that examine various physical properties related to textiles and garments. Instead of reviewing those studies assessing objective quality in the context of textile science and technology (requiring, for example, the expertise of textile engineering), the focus of this paper is on perceived quality.

Studies reviewed in this paper were searched through the database of Scopus using the following keywords: "clothing," "garment," "fashion," "apparel," "quality," "lifetimes" and "lifespan." The search yielded a total of 573 titles of articles that were screened, searching for topics related to the objectives of this paper. In case of suitable terms in the title, the relevance of the paper was determined by scanning through the keywords and abstract, and further, through the entire article. Two search modes are recommended to ensure all the relevant studies are discovered that may not appear in the database search due to the potentially inconsistent keywords or indexing (Whittemore and Knafl, 2005). Therefore, six established and relevant journals from the field of fashion/clothing/apparel journals were reviewed in more detail by browsing manually through all the titles of the selected journals over the period of past ten years (2009-2020); for the manual search, the timeframe of ten years was considered to cover the most recent research. The second phase of the search was conducted with the same approach regarding keywords and screening procedure. Additional literature considered useful for this study was found by reviewing citations from articles obtained through the search.

There are countless studies on clothing and quality conducted using various methods. This paper does not aim to cover them all. The studies included in this review were evaluated by considering how the paper helps expanding the understanding of quality, providing insight particularly to (1) perceived quality in the context of clothing and/or (2) the links between quality and clothing lifespan. Also, in most of the chosen articles, the main body of the text referred to quality; therefore, studies that merely mentioned quality but did not specifically contribute to developing that understanding were excluded. Based on the survey described above, 40 selected research articles and seven other works, such as conference

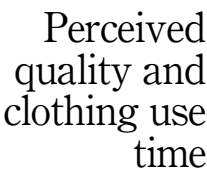


JFMM

26,1 papers and reports (total of 47), were included in this review (Appendix); this number does not include the literature used specifically in the Theoretical background section, which discusses quality as a general concept.

The idea was not to analyze and categorize the various research set-ups but to gather overarching themes of these studies to serve as an informative summary to different approaches to quality in the context of clothing. The literature resulting from the survey was organized conceptually in order to introduce the main themes of the reviewed studies. Applying a thematic analysis method, the content of each study was reduced by identifying, extracting and coding its main ideas into a manageable framework (cf. Whittemore and Knafl, 2005). The data were then examined by comparing item by item to identify patterns, themes and/or relationships so that similar data were categorized and grouped together into themes, and further into subthemes (Braun and Clarke, 2006). Each theme was named according to its core content presented in the Summary of the review section. Lastly, as one of the aims of an integrative literature review is to highlight the core issues and weave streams of research together (Torraco, 2005), this paper aims to give a comprehensive portrayal of the topic (Whittemore and Knafl, 2005) by synthetizing the main ideas into a conceptual map (Figure 1) and discussing the core issues in relation to the research question.

\section{Summary of the review}

This section presents a summary of the reviewed articles. The main ideas from the articles are thematized into the following three sections related to the perception and evaluation of quality: the process of assessment, levels involved in assessment and multidimensional cues of assessment. The fourth section, quality and clothing use times, summarizes specifically the studies related to garment use and disposal. These sections represent the main themes and discussions of the reviewed studies. Each theme is divided into subthemes to introduce the main ideas in more detail.

\section{The process of assessment}

Assessing quality is a subjective process. Consumers evaluate the quality of clothing at various phases, as a process affected by different, often subjective, factors (e.g. Abraham-Murali and Littrell, 1995; Connor-Crabb and Rigby, 2019; Koskennurmi-Sivonen and Pietarila, 2005). Abraham-Murali and Littrell (1995) consider perceived quality as a process that starts at the time of purchase and continues actively after the purchase, into consumption phase. Consumers' assessment of quality changes over time; at the pre-purchase phase, the evaluation is influenced by different expectations about the garment, and at the post-purchase, consumption phase evaluation is based on the experience of using the garment after becoming more informed about the garment and the importance of its attributes (Abraham-Murali and Littrell, 1995). In the similar vein, Björk (2014) distinguishes two phases of evaluation and names them as (1) quality cues and expectations (cf. Garvin, 1988) and (2) quality experience (cf. Lillrank, 1998). "Quality cues" refer to the different aspects that influence the expectations about product quality. These include the product itself, its price, the place of purchase and the ways of promotion - generally known as the 4P-model of marketing (e.g. Jackson and Shaw, 2009). "Quality experience" refers to the assessment of garment quality during the use-phase and is based on the consumer's own experience (Björk, 2014).

Connor-Crabb and Rigby (2019) also identify two stages of evaluation and use similar terminology: (1) the "pre-use" phase, referring to the objective quality of the garment and (2) the "during use" phase, referring to subjective quality, particularly the relationships between garment quality, user behavior and perceptions during use. They highlight that perceiving quality is connected to our everyday life experiences and to the context within which clothing is used, including the way of wearing and laundering of clothing. While on the one hand, 
objectively measurable attributes of garments generally conceptualize quality as static properties, on the other hand, these physical characteristics can be interpreted in individual ways influenced by many factors. The perception of quality can also change over time (Connor-Crabb and Rigby, 2019).

In the context of custom-made clothing, Koskennurmi-Sivonen and Pietarila (2005) distinguish three particular points of quality assessment: (1) before ordering a custom-made garment the reputation of the (dress)maker is key for estimating the quality of garments he/ she produces, (2) during design and making, quality can be assessed through style, fit, features and construction of the garment and (3) during the use and storage, the "realized quality" indicates, for example, the performance and durability of the garment itself (Koskennurmi-Sivonen and Pietarila, 2005).

Personal factors influencing assessment. Several studies have investigated the different factors that influence the way garment quality is evaluated and perceived. Studies by Apeagyei et al. (2013), Gitimu et al. (2013) and Hines and Swinker (2001) all conclude that the knowledge of clothing and textiles plays a role in the assessment process. For example, according to Apeagyei et al. (2013), professionals are better at determining garment quality compared to consumers. A study by Gitimu et al. (2013) indicated that the assessment of garment quality is significantly influenced by the level of involvement in fashion. They assume that the consumers that are actively involved in fashion spend more time and effort in acquiring information about fashion, and thus have more knowledge and relevant cues for evaluating garment quality than individuals who are less involved (Gitimu et al., 2013). Investigating various factors between apparel design, consumer demand and product quality, Huang and Tan (2007) found a large conceptual gap between the quality desires of consumers and the factors considered important by clothing designers. This is in line with Swinker and Hines's (2006) assumption that quality requirements may be different to consumers than to garment industry professionals.

Demographic factors may also have an effect on assessing quality. According to Jin $e t$ al. (2010), cultural and regional differences may influence the evaluation of garment attributes at the point of purchase; for example, different aspects are prioritized in a different cultural context. Pujara and Chaurasia's (2010) study also indicated that both gender and location had an impact on the evaluation of quality.

\section{Levels involved in assessment}

Material level. A fundamental level of evaluation focuses the material properties of the product, answering the question, "what the item is?" (De Klerk and Lubbe, 2008). This level involves the intrinsic physical characteristics of the item, such as design, textiles, construction and finishes, which could mostly be named also as objective or technical quality features (De Klerk and Lubbe, 2008). Several studies discuss attributes that are considered important aspects of quality, for example, fabric (Hines and O'Neal, 1995), fit (De Klerk and Tselepis, 2007), color and aesthetics (De Klerk and Lubbe, 2008). The list here is incomplete; as shown above, different studies identify different attributes as the most important ones. Also, the same attributes may reflect a different meaning to each person (Hines and O'Neal, 1995).

Behavioral level. Besides the material level, garments have a "behavioral dimension," which refers to the functional and aesthetic characteristics, such as durability, comfort and beauty (De Klerk and Lubbe, 2008). De Klerk and Lubbe (2008) explain that at the point of purchase, the consumer may consider "what the item can and will do for me (p. 47)," suggesting, what kind of emotions and inner experiences the garment can evoke when wearing it. This indicates a linkage between the physical properties and the behavioral qualities of the garment; the material qualities of the product influence the behavioral characteristics. This level can be dissected into the dimensions of an aesthetic experience,

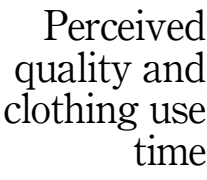

113 
JFMM

26,1

114

namely, sensory, emotional and cognitive dimensions. The sensory dimension refers to sight and touch, created especially by color and texture of the fabric. The emotional dimension describes the emotional pleasure and an inspiration stimulated by the garment. The cognitive dimension indicates how the garment conveys messages and helps the wearer experience being a part of the current cultural and social environment (De Klerk and Lubbe, 2008).

Hines and O'Neal (1995) also acknowledge the behavioral level and examine particularly the underlying meanings of the quality attributes used by consumers. For example, "fabric" was mentioned as an important quality attribute by most of the consumers, but it did not hold the same meaning for all. For one person, "fabric" was connected to high quality, and further linked to feeling good about oneself (self-esteem) and creating a good image to other people (social recognition). For another person, "fabric" was linked to garment longevity, and further connected to the monetary value of garments. The study uncovers the links between concrete quality attributes and the motives behind them, and lastly demonstrates their connection to personal values (Hines and O’Neal, 1995).

\section{Multidimensional cues of assessment}

Multiple cues are used in evaluation. Several studies conclude that consumers use multiple cues to evaluate garment quality, and the perception of quality is multidimensional (e.g. Gitimu et al., 2013; Kim, 2010; Pujara and Chaurasia, 2010; Rayman et al., 2011; Swinker and Hines, 2006). For example, Swinker and Hines (2006) studied consumers' use of informational cues in the evaluation of clothing quality, such as intrinsic (fabric and workmanship), extrinsic (brand and price), appearance (style and fit) and performance (durability and wrinkle resistance). The respondents of this study reported using most of these cues when evaluating clothing quality, which suggests that the perception of clothing quality is multidimensional. According to the results, $100 \%$ of the respondents used appearance cues, $80 \%$ used performance cues and 67\% used extrinsic cues (Swinker and Hines, 2006).

Aesthetic cues are significant. As discussed in many studies, aesthetics cues, such as style, shape and fashionability, are essential in quality assessment (e.g. De Klerk and Lubbe, 2008; Fiore and Damhorst, 1992; Lennon and Fairhurst, 1994; Scheller and Kunz, 1998; Swinker and Hines, 2006). As De Klerk and Lubbe (2008) comment, aesthetic qualities of garments may appear so significant that they may overshadow functional needs. Therefore, in order to provide a satisfactory product for a consumer, equal attention should be given to the aesthetic quality of a garment as to technical and functional features (De Klerk and Lubbe, 2008).

Extrinsic cues, such as brand, price, reputation, country of origin and marketing, are also often used as part of quality evaluation. The brand name and its reputation may give clues about the anticipated the quality. The ways of marketing influence the perception (e.g. media coverage, recommendations and trends), and so does the place of purchase, the store and the overall shopping environment (Bubonia, 2014; Jackson and Shaw, 2009; KoskennurmiSivonen and Pietarila, 2005). How much these elements affect the perception of quality is another question, as studies have come to different conclusions. For example, Forsythe (1991) found no significant relationship between brand name and perception of quality, and argues that consumers rely primarily on actual garment characteristics (intrinsic cues) rather than on brand name, as an indicator of garment quality. On the contrary, Erdogmus and BüdeyriTuran (2011) studied the effects of symbolic brand associations, brand prestige and perceived quality to brand loyalty. According to them, perceived quality had direct effects on brand attitude and loyalty. The responses also indicated that a prestigious brand signifies quality to consumers.

In some studies, price is recognized as an indicator of quality (e.g. Connor-Crabb and Rigby, 2019; Jin et al., 2010; Heisey, 1990; Lee and Chen-Yu, 2018); however, it does not necessarily reflect the objective quality of the product. Farashahi et al. (2018) examined the 
relationships between price and product quality by assessing the appearance and performance characteristics of denim jeans at three different price categories. The higher priced jeans had better product specifications and visual appearance, but the jeans of lower price points performed better in certain durability tests. The jeans in the least expensive category had initially accurate fit measurements, but their fit changed drastically after laundering. As conclusion, the price point may reflect some but not necessarily all the different dimensions of product quality (Farashahi et al., 2018). Lee and Chen-Yu (2018) explored the affective influences of price discounts in relation to consumers' perceptions on quality. The study revealed that the direct and indirect influences of price discounts on perceived apparel quality were both significant, but in opposite direction; discounts may create both positive and negative influences on consumers' perceptions on quality (Lee and Chen-Yu, 2018).

The context of online shopping limits the use of some of the cues of quality perception, such as the tactile handling of the product, and this could influence their choices, expectations and eventually satisfaction with clothing purchases. Therefore, Retief and de Klerk (2003) suggest developing a guide for evaluating quality visually that could help consumers in the decision-making process.

\section{Quality and clothing use time}

Quality is a fundamental aspect of the durability and usability of clothing, and thus plays a role on its lifespan. Increasing the number of times garments are worn and extending their lifetime are widely proposed approaches of sustainability. Producing clothes of higher quality could help lengthen their use time. This approach would potentially decrease clothing production, distribution and retail, and thus reduce the environmental impacts of textile systems (Connor-Crabb and Rigby, 2019; Cooper et al., 2013; Ellen MacArthur Foundation, 2017; Klepp et al., 2020; Laitala et al., 2015; Niinimäki et al., 2020; Watson et al., 2017).

There are several ways to calculate clothing lifespans: they can be measured in years, the number of wears, cleaning cycles and users. These methods indicate different central aspects of clothing lifespans (Klepp et al., 2020). Each time a product fails, consumers have to weigh whether it makes economically more sense to repair the old product or to invest in a new one (Garvin, 1988). Fletcher (2012, p. 226) points out that "a garment will last only as long as its least durable component," and therefore, when aiming for a product of long-lasting quality, its physical durability has to be designed as consistent as possible, including materials, components and workmanship. Focusing on better garment quality increases their durability, and thus enables increased use times, but also allows alternative and extended usership through the possibilities of renting, leasing, repairing and reselling (Ellen MacArthur Foundation, 2017; Niinimäki et al., 2020).

Quality defects as a reason for disposal. In their study discussing potential design approaches for extending product lifetimes, Laitala et al. (2015) registered 70 different reasons for clothing disposal, including defects in the garment, size and fit issues, changes in style, matters with taste and situational reasons. Deficiencies in the technical quality were the largest group of reasons for disposal, and in that, the most common reasons were holes or tears in the garment. Other common reasons were, for example, worn appearance, stains, fading of color, loss of elasticity, change of shape and pilling (Laitala et al., 2015). Similar results were reported in a study amongst Chinese consumers; $72.4 \%$ of the respondents mentioned "wear and tear" as a common reason to discard clothing (Zhang et al., 2020).

The study by Birtwistle and Moore (2007) is one of the early works to explore the underlying motives behind the purchase, consumption and disposal of fashion products. Their study reported that cheaper clothing items bought from the so-called "fast fashion" stores were quickly unwearable for three main reasons: lower quality, new fashion trend or an intention to use it for a one-off event. Collett et al. (2013) reported similar findings in their

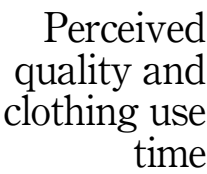

115 
JFMM

26,1

study; moreover, the responses also indicated that wearing items with such failures would communicate to others a lack of caring about oneself and possibly reflect negative personality traits. According to them, clothing lifespan was based on low technical quality rather than on fashion change.

Quality enables second-hand sales. According to McNeill et al. (2020), there is a likelihood that perceived quality positively influences attitudes toward garment life extension strategies. Quality considered as durability is a crucial aspect of garments in the secondhand markets, which enable extending the garment use times after the initial user (Cassidy, 2017; Sihvonen and Turunen, 2016). According to Sihvonen and Turunen (2016), quality appeared as a central aspect in online second-hand markets for fashion goods, and was also one of the factors construing the perceived value of a product. Investigating consumers' motivation for purchasing second-hand clothing, Machado et al. (2019) found out that some consumers considered thrift stores a place to get high-quality items at low prices. For them it also represented ethical consumption, since buying high-quality second-hand clothes enables prolonging the lifespan of existing products and avoiding the traditional fashion production chain. Hur (2020) reports similar results amongst regular second-hand consumers, but also found out that consumers generally not making second-hand purchases are reversely doubtful about product quality and cleanliness.

Ideology of use matters. Clothing lifespan is determined not only by the physical durability but also by many other factors. According to Cox et al. (2013), product lifespan is an outcome of the functional durability of a product and the actual use time, which is decided by the consumers; the use time is affected by individual factors (such as identity, personal needs and emotional attachment), societal environment and marketing. Similarly, Fletcher (2012) argues that the longevity of garments is dependent not only on material quality and durability but also on user behavior and consumption patterns that are influenced by social and experiential context. Clothing use time is related to aesthetics, social preferences, and the ideology of use (Fletcher, 2012). As quality is experienced in personal and individualized ways in everyday use, and also tied into user practices, this has an effect for how long the garment is in use (Connor-Crabb and Rigby, 2019). For example, for some consumers, high quality is associated with luxury products, typically composed of high quality of materials with an emphasis on design and originality, and such products can be assumed to have a long lifespan (Cassidy, 2017). For some others, the product is good enough when it satisfies their perception of minimum performance and manufacturing standards (Jackson and Shaw, 2009). Especially regarding "fast fashion" items, consumers are willing to compromise quality and durability for lower price as it "allows dreams of luxury to come true" even without a high-price ticket (Joy et al., 2012, p. 286); low prices justify the diminished quality and short use time (Collett et al., 2013). Gabrielli et al. (2013) investigated the consumption practices of fast fashion products, focusing particularly on the individual and socio-cultural dimensions of consumption. Based on the study, for post-modern consumers, the symbolic meanings encoded in fast fashion goods and retail settings are means to express their identity and lifestyle. Thus, consumers are willing to compromise quality and durability for experiencing freedom to construct and alter their own style frequently (Gabrielli et al., 2013).

\section{Discussion}

This paper explores how quality is conceptualized in the context of clothing and examines potential connections between quality and garment use time. It also aims to provide a synthesis of concepts from the selected literature that may enable better understanding of the perceived quality of clothing. Applying concepts and perspectives of the reviewed studies and also of general literature of quality, this paper maps out the relevant aspects of perceived quality in the context of clothing in the following way (Figure 1): 


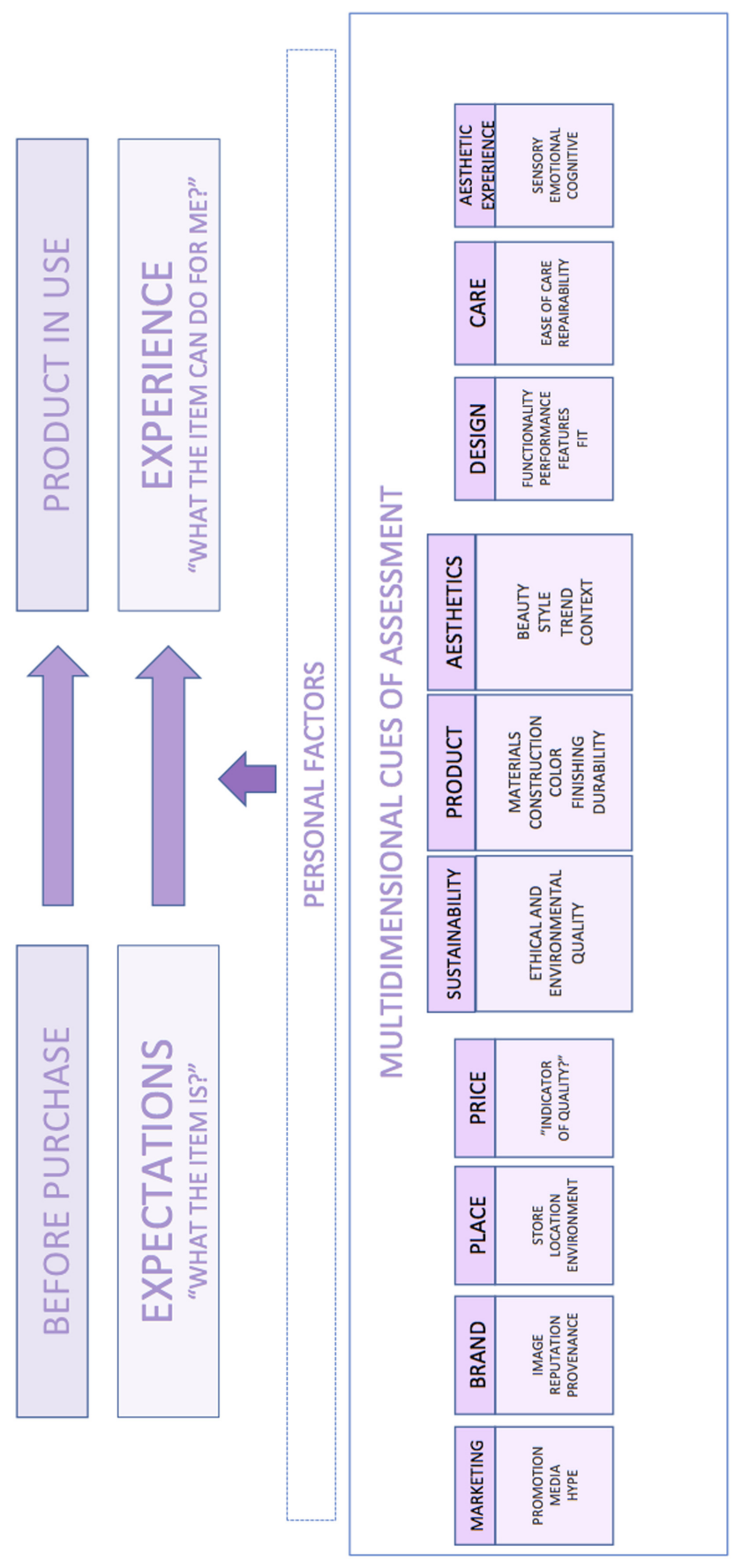

Perceived quality and clothing use time

Figure 1.

The process of perceiving quality in the context of clothing 
JFMM

26,1

118

This map integrates the main elements of perceived quality as extracted from the literature and discussed in the earlier sections of this paper. It depicts the three main themes emerging from the literature - the process of assessment, levels involved in the assessment and multidimensional cues of assessment - and their different elements. Each concept may include more notions than the ones mentioned here, and the concepts may overlap somewhat.

Firstly, the figure shows the process of assessment, referring to the two main phases of quality assessment: (1) before purchase and (2) product in use (e.g. Abraham-Murali and Littrell, 1995). Secondly, conceptual processes, representing the theme of levels involved in assessment, influence the process of evaluation; they are named here as (1) expectations and (2) experience. The label "Expectations" refers also to the time "Before purchase" (or any other way to obtain a garment; could be also renting, borrowing or receiving a garment), and therefore indicates the first phase of evaluation. It can be illustrated through the question, "What the item is?" "Experience" refers to the second phase of evaluation, "Product in use," and therefore, to the insight gained by personal experience. Through experience, one may gain more understanding about the question, "What the item can do for me?" (cf. De Klerk and Lubbe, 2008). These questions concern each phase respectively but also simultaneously. Here, different personal factors influence and shape the perceiving of quality. These include the knowledge of clothing and textiles (e.g. Apeagyei et al., 2013), and demographic factors such as culture and gender (e.g. Jin et al., 2010).

The third theme, multidimensional cues of assessment, is presented in the figure as several smaller categories, that is, informational cues used in the evaluation. The concepts of price, place, brand and marketing play a role particularly at the time before purchase, and thus may influence the expectations. The concepts of design, care and aesthetic experience concern more the functionality of the product, and therefore the use-phase; these quality assessment cues are gained through the experience of using the product. Three concepts in particular, product, aesthetics and sustainability, are placed between the two phases of evaluation, depicting that these are considered significantly during both phases, fundamentally affecting the entire assessment of quality.

All concepts of the figure have been discussed in detail in the earlier sections of the paper, and the related keywords are placed within each particular concept. For example, "Product" refers to the material features of the garment, such as construction, materials color and finishing; these indicate elements of objective quality and communicate, for example, the durability of garment. "Aesthetics" include the ideas of beauty, style and trend, and this evaluation is essentially influenced by the context where the garment is going to be used. The "aesthetic experience" is identified as a distinct concept, referring to what feelings, emotions and thoughts the garment evokes, thus involving the sensory, emotional and cognitive dimensions of the individual (De Klerk and Lubbe, 2008).

Lastly, to clarify, "Sustainability" refers here to the ethical and environmental quality, and how it has been realized and communicated to consumers. According to the system-based view of quality in general, ethical and environmental matters are essential aspects of the overall quality of any product; it implicates that a good-quality product should not have a negative impact on the environment (Lillrank, 1998). In today's context, considering the existing knowledge on the impacts of clothing and textile manufacturing (e.g. Ellen MacArthur Foundation, 2017), the system-based view of quality (Lillrank, 1998) can be argued as a requirement of good quality. In this conceptual map, sustainability is assumed to be significant during both phases of quality assessment, and therefore to shape the entire perception of quality. It can be considered as a credence attribute that cannot be noticed directly through use, but can be acknowledged through the additional information given by experts (cf. Steenkamp, 1990).

This figure illustrates that quality assessment is an individual conceptual process that is influenced by different cues and factors. While the two phases of assessment can be clearly 
separated, the perception of quality is a process that evolves (Abraham-Murali and Littrell, 1995; Connor-Crabb and Rigby, 2019). Thus, the different aspects influencing the individual expectations and experience most likely play some role in both phases. Some aspects considered before the purchase may be meaningful in the use-phase; for example, "Brand" may be connected to self-esteem and social recognition, and therefore affects the experience of wearing the garment (cf. Hines and O'Neal, 1995). The figure is a conceptual map that aims to simplify and illustrate the complex assessment process and its elements.

Regarding the second research question, this paper investigates links between quality and clothing use times. Figure 2 depicts how objective and perceived quality both play a role in clothing use time. Physical features of clothing affect the perceiving of quality, and therefore using both types of cues, consumers assess the quality of clothing and determine how long the clothing is in use. As visualized in this figure, clothing lifespan covers more than individual ownership and use time (Klepp et al., 2020); it refers to the ownership of clothing, but also to all other ways of use, such as renting and borrowing. It also covers other ways of extending the use time after the first ownership, such as second-hand market and donations, and also the potentials of modifications and upcycling.

\section{The limitations of the study}

The summary of articles presented in this paper is based on an integrated literature review, which does not aim at an all-inclusive review of existing studies. Instead, it aims to generate new perspectives to a mature topic by using selected literature (Torraco, 2005). Therefore, the results of the study do not provide statistical data or the exhaustive summaries of existing studies, but a qualitative synthesis of the chosen subject. The literature has been gathered around the topic and the research questions with an intention to bring attention to the potential links between quality and use time of clothing in the context of sustainability. The conceptualizations emerge from the review; however, there are obviously countless ways to identify and thematize the core ideas of the reviewed studies. A systematic survey was supplemented by manual literature search to discover all the potential studies to be included in the review; however, due to search criteria, it is possible that not all the relevant existing studies were found. As for validity of this study, the paper has aimed to be grounded on the data and to include and summarize all the core areas of the reviewed studies.

The review also shows that some research results are contradictory. For example, there is no consensus about the most important aspect of quality. As Lennon and Fairhurst (1994) mention, findings from different studies related to the assessment of perceived quality of clothing are sometimes inconsistent, perhaps due to the different methods of operationalizing and measuring quality. Therefore, this paper gathers the many aspects related to perceived quality of clothing.

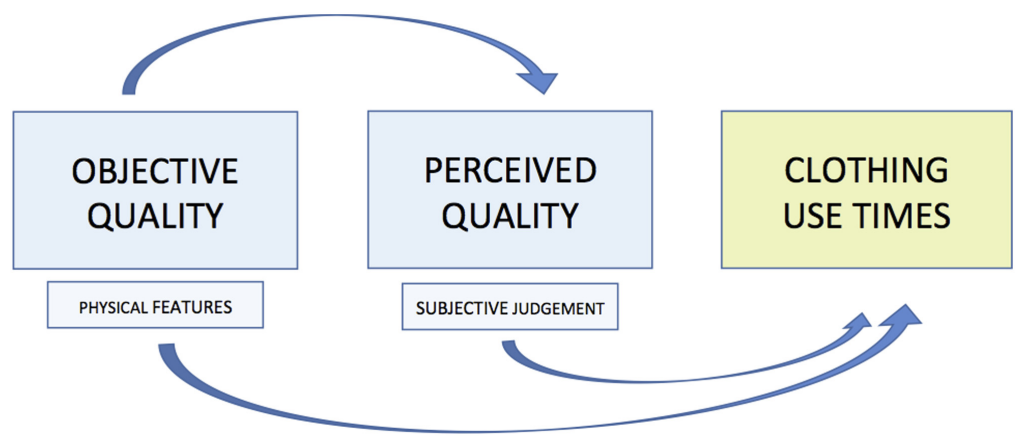

Perceived quality and clothing use time

119
Figure 2.

The relationship between objective and perceived quality and clothing use times 
JFMM

26,1

120

\section{Conclusion}

This paper outlines perspectives to quality on a general level and reviews the current literature of perceived quality of clothing. Integrating the key concepts of quality from the reviewed literature, the relevant aspects are assembled into a conceptual map (Figure 1) that represents particularly a users' point of view to evaluating quality. It aims to illustrate that for a consumer, assessing quality is a process that is shaped first by the expectations of the garment, and further by the experience of using it. The conceptual map presents aspects gathered from the literature, yet it does not place them in any order regarding their priority, as the significance and weight of different quality attributes may be individual and related to the context (Connor-Crabb and Rigby, 2019; Zeithaml, 1988). However, there is an assumption that certain concepts concern more either the first or the second phase of the assessment.

While this paper focuses on perceived quality, the importance of objective quality is not overlooked; in order to have a general view of quality, both perspectives are necessary. Figure 2 aims to illustrate how both objective quality and perceived quality matter in determining the use time of clothing. Objective quality communicates measurable information, for example, about the durability of materials, which cannot be merely perceived and estimated by senses. The viewpoint of perceived quality is obviously subjective, and therefore imperfect to actually measure aspects of quality. Yet, even the objective quality is perceived and experienced in individual ways in everyday life, and this influences how long the garment is in use (ConnorCrabb and Rigby, 2019). Therefore, understanding the concept of quality from the user's perspective is essential for gaining knowledge of garment lifetime in relation to sustainability strategies.

This paper illustrates how multifaceted the concept of quality is and how the individual context - including expectations and experiences - influences the interpretations of quality. As pointed out by Huang and Tan (2007), there may be a gap between what consumers desire and what designers think they desire in terms quality. In order to improve clothing quality, besides developing physical features, there is a need to understand what kinds of cues indicate quality to consumers. Moreover, it is necessary to understand how this information could be applied in the design and production phases as well as in the communicating of technical quality features to consumers. A toolbox that can be used in context-specific situations in the industry could be useful (cf. Stylidis et al., 2020). Many of the reviewed studies highlighted the importance of aesthetics as a significant criterion of quality to consumers, which indicates that aesthetic aspects should not be omitted when developing technical quality features.

As for managerial implications, the paper serves as an integrated review of the elements of quality to be considered in the design and production process, but also aims to inspire to develop the ways of communicating quality to consumers. In addition, the paper brings closer the topics of quality and clothing use time, calling attention to the need for further studies. Against the backdrop of the significantly increased clothing production and simultaneously decreased clothing utilization (Ellen MacArthur Foundation, 2017), more ideas to tackle this challenge and the consequences are welcome. It must be noted that sustainable strategies, such as producing better quality, do not necessarily decrease environmental impact, if consumers do not lower their consumption and if the total amount of clothing production does not decrease (Niinimäki and Hassi, 2011; Maldini and Balkenende, 2017). At the moment, the strategy of reducing clothing demand on the basis of product longevity is yet on a conceptual level and requires further research (Maldini et al., 2019). While extending product use time can be argued as a reasonable approach to decrease the excessive production of clothing and to lower clothing consumption, in theory the following question remains: Will consumers purchase less clothing and use their existing clothing longer if they were of better quality?

For researches, it provides a reference to several themes to be explored further. The field would benefit on studies that investigate the connections between the quality, sustainability 
and garment lifespans, examining, for example, whether consumers will purchase less clothing if the quality was better. Also, as producing better quality might raise the price point, how much would consumers be willing to pay more for better quality. Further studies could also examine particularly consumers' perceptions and desires on quality requirements; in other words, what exactly is the level of quality they are satisfied with. One stream of research could focus on the challenges related to the evaluation of quality in online shopping, as the assessment does not involve the tactile cues, such as feeling the fabric. More research could also be conducted by exploring companies' efforts to communicate quality to consumers. As mentioned by Garvin (1988), sometimes an improvement on one dimension of quality may be achieved at the expense of another one; therefore, careful calculations of the pros and cons should be done in order to reach environmental benefits through the possibilities of quality.

\section{References}

Abraham-Murali, L. and Littrell, M.A. (1995), "Consumers' perceptions of apparel quality over time: an exploratory study", Clothing and Textiles Research Journal, Vol. 13 No. 3, pp. 149-158.

Anttila, J. and Jussila, K. (2017), "Understanding quality - conceptualization of the fundamental concepts of quality", International Journal of Quality and Service Sciences, Vol. 9 Nos 3/4, pp. 251-268, doi: 10.1108/IJQSS-03-2017-0020.

Apeagyei, P.R., McLoughlin, J. and Omidvar, L. (2013), "Consumers and professionals perceptions of garment quality for a selection of women's vests", International Journal of Fashion Design, Technology and Education, Vol. 6 No. 1, pp. 2-9, doi: 10.1080/17543266.2012.710649.

Birtwistle, G. and Moore, C.M. (2007), "Fashion clothing - where does it all end up?", International Journal of Retail and Distribution Management, Vol. 35 No. 3, pp. 210-216, doi: 10.1108/ 09590550710735068.

Björk, H. (2014), “Laatu Vaatteessa. Vaatteen Laatukäsite Kuluttajan Näkökulmasta”, Master's thesis, University of Lapland, Rovaniemi.

Braun, V. and Clarke, V. (2006), "Using thematic analysis in psychology", Qualitative Research in Psychology, Vol. 3 No. 2, pp. 77-101.

Bubonia, J.E. (2014), Apparel Quality. A Guide to Evaluate Sewn Products, Fairchild, New York.

Cassidy, T.D. (2017), "Conceptualizing sustained high quality fashion products in a devalue dominated marketplace", Fashion Practice, Vol. 9 No. 2, pp. 235-253, doi: 10.1080/17569370.2016. 1220136.

Collett, M., Cluver, B. and Chen, H.-L. (2013), "Consumer perceptions the limited lifespan of fast fashion apparel”, Research Journal of Textile and Apparel, Vol. 17 No. 2, pp. 61-68.

Connor-Crabb, A. and Rigby, E.D. (2019), "Garment quality and sustainability: a user-based approach”, Fashion Practice, Vol. 11 No. 3, pp. 346-374, doi: 10.1080/17569370.2019.1662223.

Cooper, T., Hill, H., Kininmonth, J., Townsend, K. and Hughes, M. (2013), "Design for longevity: guidance on increasing the active life of clothing", WRAP (Waste \& Resources Action Programme), Oxon, available at: http://www.wrap.org.uk/sites/files/wrap/Design $\% 20$ for $\%$ 20Longevity\%20Report_0.pdf (accessed 20 March 2020).

Cooper, T., Claxton, S., Hill, H., Holbrook, K., Hughes, M., Knox, A. and Oxborrow, L. (2014), Clothing Longevity Protocol, Nottingham Trent University, Banbury.

Cox, J., Griffith, S., Giorgi, S. and King, G. (2013), "Consumer understanding of product lifetimes", Resources, Conservation and Recycling, Vol. 79, pp. 21-29.

Day, C., Beverley, K. and Lee, A. (2015), "Fast fashion, quality and longevity: a complex relationship", in Cooper, T., Braithwaite, N., Moreno, M. and Salvia, G. (Eds), Proceedings of the Product Lifetimes and the Environment (PLATE) Conference 2015, Nottingham Trent University, Cadbe, pp. 100-106.
Perceived quality and clothing use time 
JFMM

26,1

122

De Klerk, H.M. and Lubbe, S. (2008), “Female consumers' evaluation of apparel quality: exploring the importance of aesthetics", Journal of Fashion Marketing and Management, Vol. 12 No. 1, pp. 36-50, doi: 10.1108/13612020810857934.

De Klerk, H.M. and Tselepis, T. (2007), "The early-adolescent female clothing consumer. Expectations, evaluation and satisfaction with fit as part of the appreciation of clothing quality", Journal of Fashion Marketing and Management, Vol. 11 No. 3, pp. 413-428.

Ellen MacArthur Foundation (2017), "A new textiles economy: redesigning fashion's future”, available at: https://www.ellenmacarthurfoundation.org/publications/a-new-textiles-economyredesigning-fashions-future (accessed 19 March 2020).

Erdogmus, I. and Büdeyri-Turan, I. (2011), "The role of personality congruence, perceived quality and prestige on ready-to-wear brand loyalty", Journal of Fashion Marketing and Management, Vol. 16 No. 4, pp. 399-417, doi: 10.1108/13612021211265818.

Farashahi, B.G., Easter, E. and Annett-Hitchcock, K. (2018), "Price and perceived product quality: a comparison of denim jeans in three price categories", Journal of Fashion Marketing and Management, Vol. 22 No. 3, pp. 369-386.

Fiore, A.M. and Damhorst, M.L. (1992), "Intrinsic cues as predictors of perceived quality of apparel", Journal of Consumer Satisfaction, Dissatisfaction and Complaining Behavior, Vol. 5, pp. 168-178.

Fletcher, K. (2012), "Durability, fashion, sustainability: the processes and practices of use", Fashion Practice, Vol. 4 No. 2, pp. 221-238, doi: 10.2752/175693812X13403765252389.

Forsythe, S.M. (1991), "Effect of private, designer, and national brand names on shoppers' perception of apparel quality and price", Clothing and Textiles Research Journal, Vol. 9 No. 1, pp. 1-6.

Gabrielli, V., Baghi, I. and Codeluppi, V. (2013), "Consumption practices of fast fashion products: a consumer-based approach", Journal of Fashion Marketing and Management, Vol. 17 No. 2, pp. 206-224, doi: 10.1108/JFMM-10-2011-0076.

Garvin, D.A. (1988), Managing Quality. The Strategic and Competitive Edge, The Free Press, New York.

Gitimu, P.N., Workman, J. and Robinson, J.R. (2013), "Garment quality evaluation: influence of fashion leadership, fashion involvement, and gender", International Journal of Fashion Design, Technology and Education, Vol. 6 No. 3, pp. 173-180, doi: 10.1080/17543266.2013.815809.

Golder, P.N., Mitra, D. and Moorman, C. (2012), "What is quality? An integrative framework of processes and states", Journal of Marketing, Vol. 76, pp. 1-23.

Heisey, F.L. (1990), "Perceived quality and predicted price: use of the minimum information environment in evaluating apparel", Clothing and Textiles Research Journal, Vol. 8 No. 4, pp. 22-28.

Hines, J.D. and O'Neal, G.S. (1995), "Underlying determinants of clothing quality: the consumers' perspective", Clothing and Textiles Research Journal, Vol. 13 No. 4, pp. 227-233.

Hines, J.D. and Swinker, M.E. (2001), "Knowledge: a variable in evaluating clothing quality", International Journal of Consumer Studies, Vol. 25 No. 1, pp. 72-76.

Huang, Y.Y. and Tan, B. (2007), "Applications of quality function deployment to apparel design in Taiwan”, Journal of Fashion Marketing and Management, Vol. 11 No. 2, pp. 215-237, doi: 10. 1108/13612020710751392.

Hur, E. (2020), "Rebirth fashion: secondhand clothing consumption values and perceived risks", Journal of Cleaner Production, Vol. 273, 122951.

Jackson, T. and Shaw, D. (2009), Mastering Fashion Marketing, Palgrave Macmillan, Hampshire.

Jin, B., Park, J.Y. and Ryu, J.S. (2010), “Comparison of Chinese and Indian consumers' evaluative criteria when selecting denim jeans", Journal of Fashion Marketing and Management, Vol. 14 No. 1, pp. 180-194.

Joy, A., Sherry, J.F., Venkatesh, A., Wang, J. and Chan, R. (2012), "Fast fashion, sustainability, and the ethical appeal of luxury brands", Fashion Theory, Vol. 16 No. 3, pp. 273-296, doi: 10.2752/ $175174112 X 13340749707123$. 
Karell, E. and Niinimäki, K. (2020), “A mixed-method study of design practices and designers' roles in sustainable-minded clothing companies", Sustainability, Vol. 12, doi: 10.3390/ su12114680.

Kim, J. (2010), "Perceived apparel quality revisited: testing of its structural dimensions from the perspective of the generation Y female consumers", Journal of Global Fashion Marketing, Vol. 1 No. 4, pp. 240-249, doi: 10.1080/20932685.2010.10593075.

Klepp, I.G., Laitala, K. and Wiedemann, S. (2020), "Clothing lifespans: what should be measured and how", Sustainability, Vol. 12, doi: 10.3390/su12156219.

Koskennurmi-Sivonen, R. and Pietarila, P. (2005), "Quality clothes - an outline of a model for assessing the quality of customized clothing", Proceedings of in the Making, The First Nordic Design Research Conference, Copenhagen, May 29-31, 2005.

Laitala, K., Boks, C. and Klepp, I.G. (2015), "Making clothing last: a design approach for reducing the environmental impacts", International Journal of Design, Vol. 9 No. 2, pp. 93-107.

Laitala, K. and Klepp, I.G. (2015), "Age and active life of clothing", PLATE: Product Lifetimes and the Environment, Nottingham Trent University, Cadbe, pp. 182-186.

Lee, J.E. and Chen-Yu, J.H. (2018), "Effects of price discount on consumers' perceptions of savings, quality, and value for apparel products: mediating effect of price discount affect", Fashion and Textiles, Vol. 5 No. 13, doi: 10.1186/s40691-018-0128-2.

Lennon, S.J. and Fairhurst, A.E. (1994), "Categorization of the quality concept”, Home Economics Research Journal, Vol. 22 No. 3, pp. 267-285.

Lexico (2020), "[Definition of] quality”, available at: https://www.lexico.com/definition/quality (accessed 25 March 2020).

Lillrank, P. (1998), Laatuajattelu: Laadun Filosofia, Tekniikka ja johtaminen Tietoyhteiskunnassa, Otava, Helsinki.

Machado, M.A.D., de Almeida, S.O., Bollick, L.C. and Bragagnolo, G. (2019), "Second-hand fashion market: consumer role in circular economy", Journal of Fashion Marketing and Management, Vol. 23 No. 3, pp. 382-395, doi: 10.1108/JFMM-07-2018-0099.

Maldini, I. and Balkenende, R. (2017), "Reducing clothing production volumes by design: a critical review of sustainable fashion strategies", in Bakker, C. and Mugge, R. (Eds), PLATE. Product Lifetimes and the Environment, Delft University of Technology and IOS Press, Delft, pp. 233-237, doi: 10.3233/978-1-61499-820-4-233.

Maldini, I., Stappers, P.J., Gimeno-Martinez, J.C. and Daanen, H.A.M. (2019), "Assessing the impact of design strategies on clothing lifetimes, usage and volumes: the case of product personalisation", Journal of Cleaner Production, Vol. 210, pp. 1414-1424.

McNeill, L.S., Hamlin, R.P., McQueen, R.H., Degenstein, L., Wakes, S., Garrett, T.C. and Dunn, L. (2020), "Waste not want not: behavioural intentions toward garment life extension practices, the role of damage, brand and cost on textile disposal", Journal of Cleaner Production, No. 260, doi: 10. 1016/j.jclepro.2020.121026.

Niinimäki, K. (2010), "Eco-clothing, consumer identity and ideology", Sustainable Development, Vol. 18, pp. 150-162.

Niinimäki, K. (2015), "Sustainable consumer satisfaction in the context of clothing", in Vezzoli, C., Kohtala, C., Srinivasan, A., Diehl, J.C., Fusakul, S.M., Xin, L. and Sateesh, D. (Eds), ProductService System Design for Sustainability, Greenleaf, Sheffield, pp. 218-237.

Niinimäki, K. and Hassi, L. (2011), "Emerging design strategies in sustainable production and consumption of clothing", Journal of Cleaner Production, Vol. 19, pp. 1876-1883.

Niinimäki, K., Peters, G., Dahlbo, H., Perry, H.P., Rissanen, T. and Gwilt, A. (2020), "The environmental price of fast fashion", Nature Reviews Earth Environment, Vol. 1, pp. 189-200, doi: 10.1038/ s43017-020-0039-9.

\section{Perceived quality and clothing use time}


JFMM 26,1

Olson, J.C. and Jacoby, J. (1972), "Cue utilization in the quality perception process", in Venkatesan, M. (Ed.), SV - Proceedings of the Third Annual Conference of the Association for Consumer Research, Association for Consumer Research, Chicago, IL, pp. 167-179.

Pujara, T. and Chaurasia, S. (2010), "Understanding the young consumers' perception of clothing quality", Journal of Management Research, Vol. 1 No. 2, pp. 53-61.

Rayman, D., Burns, D.J. and Nelson, C.N. (2011), "Apparel product quality: its nature and measurement”, Journal of Global Fashion Marketing, Vol. 2 No. 2, pp. 66-75, doi: 10.1080/ 20932685.2011.10593084.

Reeves, C.A. and Bednar, D.A. (1994), "Defining quality: alternatives and implications”, The Academy of Management Review, Vol. 19 No. 3, pp. 419-445.

Retief, A. and de Klerk, H.M. (2003), "Development of a guide for the visual assessment of the quality of clothing textile products", Journal of Consumer Sciences, Vol. 31, pp. 21-29.

Scheller, H.P. and Kunz, G.I. (1998), “Toward a grounded theory of apparel product quality”, Clothing and Textiles Research Journal, Vol. 16 No. 2, pp. 57-67.

Sihvonen, J. and Turunen, L.M.M. (2016), "As good as new - valuing fashion brands in the online second-hand markets", The Journal of Product and Brand Management, Vol. 25 No. 3, pp. 285-295.

Steenkamp, J.-B.E.M. (1990), "Conceptual model of the quality perception process", Journal of Business Research, Vol. 21, pp. 309-333.

Stylidis, K., Wickman, C. and Söderberg, R. (2020), "Perceived quality of products: a framework and attributes ranking method", Journal of Engineering Design, Vol. 31 No. 1, pp. 37-67.

Swinker, M.E. and Hines, J.D. (2006), "Understanding consumers' perception of clothing quality: a multidimensional approach", International Journal of Consumer Studies, Vol. 30 No. 2, pp. 218-223, doi: 10.1111/j.1470-6431.2005.00478.x.

Torraco, R.J. (2005), "Writing integrative literature reviews: guidelines and examples", Human Resource Development Review, Vol. 4 No. 3, pp. 356-367, doi: 10.1177/1534484305278283.

Watson, D., Gylling, A.C. and Thörn, P. (2017), "Business models extending active lifetime of garments: supporting policy instruments", Mistra Future Fashion Report, PlanMiljø, Veksø Sjælland and IVL Svenska Miljöinstitutet, Stockholm.

Whittemore, R. and Knafl, K. (2005), "The integrative review: updated methodology", Journal of Advanced Nursing, Vol. 52 No. 5, pp. 546-553.

Zeithaml, V.A. (1988), "Consumer perceptions of price, quality, and value: a means-end model and synthesis of evidence", Journal of Marketing, Vol. 52, pp. 2-22.

Zhang, L., Wu, T., Liu, S., Jiang, S., Wu, H. and Yang, J. (2020), "Consumers' clothing disposal behaviors in Nanjing, China", Journal of Cleaner Production, Vol. 276 p. 123184. 
Journal of Fashion Marketing and Management*

Journal of Cleaner Production

Clothing and Textiles Research Journal*

Fashion Practice*

Home Economics Research Journal

International Journal of Consumer Studies

International Journal of Fashion Design, Technology and Education*

Journal of Global Fashion Marketing 2

Fashion and Textiles*

Fashion Theory* 1

International Journal of Design 1

International Journal of Retail and Distribution Management 1

Journal of Consumer Satisfaction, Dissatisfaction and Complaining Behavior 1

Journal of Consumer Sciences 1

Journal of Management and Research 1

Journal of Marketing 1

Journal of Product and Brand Management 1

Nature Reviews Earth Environment 1

$\begin{array}{lr}\text { Research Journal of Textile and Apparel } & 1 \\ \text { Sustainability } & 2\end{array}$

Table A1.

Other selected literature

Conference Proceedings

The selected articles included in this review represented the following journals the journals marked with an asterisk were included also in the manual search

\section{Corresponding author}

Maarit Aakko can be contacted at: maarit.aakko@aalto.fi

For instructions on how to order reprints of this article, please visit our website:

www.emeraldgrouppublishing.com/licensing/reprints.htm

Or contact us for further details: permissions@emeraldinsight.com 